\title{
Power quality improvement using dynamic voltage restorer in distribution system PT. DSS Power Plant
}

\author{
Wahyuni Martiningsih ${ }^{1, *}$, Untung Yudho Prakoso ${ }^{1}$, and Herudin ${ }^{1}$ \\ ${ }^{1}$ Departement Electrical Engineering, Universitas Sultan Ageng Tirtayasa, Banten, Indonesia
}

\begin{abstract}
In the power plant power system, voltage drops often occur and one of the contributing factors is a short circuit that affects the performance of motor drivers on the mills in the generator. In this research proposed the use of compensation dynamic voltage restorer (DVR) to damped voltage sag. The DVR using a three-phase voltage source inverter (VSI) with voltage loop control (PI). To detect the voltage drop system using park transform and apply it in the voltage regulator as a control system function that detects the voltage amplitude at the sensitive load continuously. The result of simulation in system distribution with active load $280 \mathrm{kVA}$ and 50 $\mathrm{kVAR}$ reactive, before a voltage compensation system $0.67 \mathrm{pu}$ and after voltage compensation system becomes $0.99 \mathrm{pu}$ on nominal voltage of $380 \mathrm{~V}$. The performance of DVR is reliable because it is able to compensate quickly to changes in the value of the voltage
\end{abstract}

\section{Introduction}

The quality of electric power becomes an important issue because the electricity that is channeled to the consumer must be really good quality. Disturbances to the electrical system can occur at any time and can't be avoided. The disturbances can come from both internal and external of the power plant system and can cause the problem of voltage drop. Voltage drop can impact the power quality of the power system.

Power quality problems are: voltage drop, flicker, voltage imbalance, disconnection and harmonic problem [1][2]. Sensitive equipment such as computers, releases, programmable logic controllers (PLC), electric motor drivers and so on, are extremely sensitive to voltage changes caused by interference with other parts of the system[3]. The voltage drop is defined as a decrease in the rms value of the voltage that can occur from $10 \mathrm{~ms}$ to $1 \mathrm{~min}$ with the depth of the falling voltage of $0.9 \mathrm{pu}$ to $0.1 \mathrm{pu}$ of a nominal pu based on the IEEE standard 1159-1995 [4][5].

In the electrical system of PT. DSS power plant, often there is a decrease of voltage and one of the causal factor is a short circuit that resulted in the performance of motor drivers on the mills in generator unit 6 . In this research will be modeling three-phase system that experienced a decrease in voltage, from the results modeling will be analyzed the voltage drop recovery that occurs with the sensitive load to be protected by the DVR from the

*Corresponding author: y_martiningsih@untirta.ac.id 
effect of the voltage drop, so that a large pattern of DC PWM inverter voltage required by the DVR in accordance with the needs of sensitive load to be protected.

\subsection{DVR}

DVR is a power electronic switching device which is connected in series to the load voltage bus to inject a dynamically controlled voltage. This voltage can eliminate effects of fault of voltage bus on a sensitive load [6].

DVR is equipment used to recover a voltage or improve the voltage quality on the load side and its position is mounted in series between the source and the load. DVRs are coupled in series with distribution systems to protect sensitive equipment against the occurrence of voltage drops ${ }^{[7],[8]}$. The basic function of the DVR is to detect the occurrence of voltage drops that occur on the power system channel, and then inject the voltage to compensate for the voltage drop that occurs. Therefore the DVR is placed close to the sensitive load that is protected.

The DVR works depending on the type of interference or an event occurring in the system, generating the injected voltage obtained from the DC energy storage unit and then converted to AC voltage by the voltage source inverter (VSI) [9]. To set the controller on the DVR is used dq0 transformation or Park transformation. The dq0 method will provide information on the depth of the voltage drop and the phase shift with the starting point and end point of the voltage drop. The transformation process from three phase system to dq0 system is shows at Equation 1[6].

$$
\left[\begin{array}{l}
V_{d} \\
V_{q} \\
V_{0}
\end{array}\right]=\frac{2}{3}\left[\begin{array}{ccc}
\cos (\omega t) & \cos (\omega t-120) & \cos (\omega t+120) \\
-\sin (\omega t) & -\sin (\omega t-120) & -\sin (\omega t+120) \\
\frac{1}{2} & \frac{1}{2} & \frac{1}{2}
\end{array}\right]\left[\begin{array}{l}
V_{a} \\
V_{b} \\
V_{c}
\end{array}\right]
$$

The DC source is a very important element for the DVR. The DC source will be converted to AC voltage by the inverter. The magnitude of the DC source will affect the magnitude of the output voltage as described in equation 3

$$
\begin{array}{r}
M_{a}=\frac{A_{r}}{A_{c}} \\
V_{D C}=\frac{V_{L L}}{0,707 M a}
\end{array}
$$

where:

$M_{a} \quad=$ amplitudee

$A_{r} \quad=$ amplitude reference

$A_{\mathrm{c}} \quad=$ amplitude of carrier

$V_{D C} \quad=$ voltage source VSI

$V_{L L} \quad=$ rms voltage line to line

\section{Metodology}

This research was conducted on a distribution channel of PT. DSS Power Plant. The research process of simulating the recovery of drop voltage can be explained through the block diagram in Figure 1.

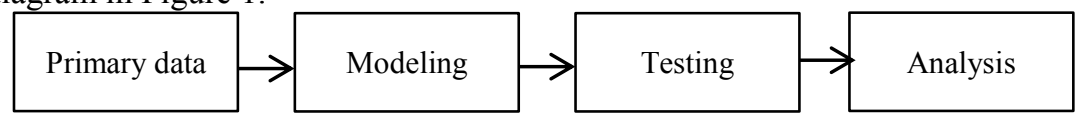

Fig. 1. Block diagram of research 
Explanation of the steps of the block diagram in Figure 1:

1. Primary data, carried out at the beginning of the study which aims to support of the research, while the data taken include voltage, current, power, frequency, and transformer specifications.

2. Modeling, that is making the design of system design as a whole.

3. Testing the simulation is to ensure that the designed DVR can work properly.

4. Analysis of the results of the simulation, data which obtained of simulation and then analyzed so that conclusions achieved.

\subsection{Parameter Model}

The parameters used in the DVR model for the distribution system of PT. DSS Serang Power Plant as shown in Table 1.

Table 1. Parameter of modeling

\begin{tabular}{l|l}
\hline \multicolumn{1}{c|}{ Parameter } & Nilai \\
\hline Source voltage & $20 \mathrm{kV}$ \\
Transformer Distribution & $2500 \mathrm{kVA}$ \\
Frequency & $50 \mathrm{~Hz}$ \\
Primary voltage & $20 \mathrm{kV}$ \\
Primary winding resistance & $2.16 \Omega$ \\
Primary winding inductance & $8.6 \mathrm{mH}$ \\
Secondary voltage & $380 \mathrm{~V}$ \\
Secondary winding resistance & $0.02 \Omega$ \\
Secondary winding inductance & $0.08 \mathrm{mH}$ \\
Magnetization resistance and reactance & $577 \Omega$ \\
P & $280 \mathrm{kVA}$ \\
Power of Inductive load & $40 \mathrm{kVAR}$ \\
Power of Capasitive load & $10 \mathrm{kVAR}$ \\
\hline
\end{tabular}

Modeling a voltage source uses a three phase system controlled voltage source. The source voltage is delivered to the load through a distribution transformer of $20 \mathrm{kV} / 380 \mathrm{~V}$. The load used in the simulation has a capacity of $280 \mathrm{kVA}$ and $50 \mathrm{kVAR}$.

\subsection{Research Design}

In this study, DVR system modelling consists of several block diagrams, including load systems, controls, inverter voltage sources, filters, and injection transformers. The research design of the DVR can be seen in Figure 2.

The inverter used is a unit of three-phase inverter circuit with the ignition switch using the SPWM method. The output voltage generated by the inverter depends on the modulation index of the SPWM and the DC source voltage rating. The inverter converts DC voltage to AC voltage. Determination of DC source capacities can be seen in equation 3. Because the rating of the primary voltage on the injection transformer is 380 volt rms and if it is known the maximum $M_{a}$ is 0.8 , then the required DC source is $672 \mathrm{~V}$.

Passive filters at Figure 3 . are composed of capacitors and inductors with a frequency that is set to the harmonic voltage frequency to be removed. Inductance and capacitance in this filter are $1 \mathrm{mH}$ and $1 \mu \mathrm{F}$ respectively. 


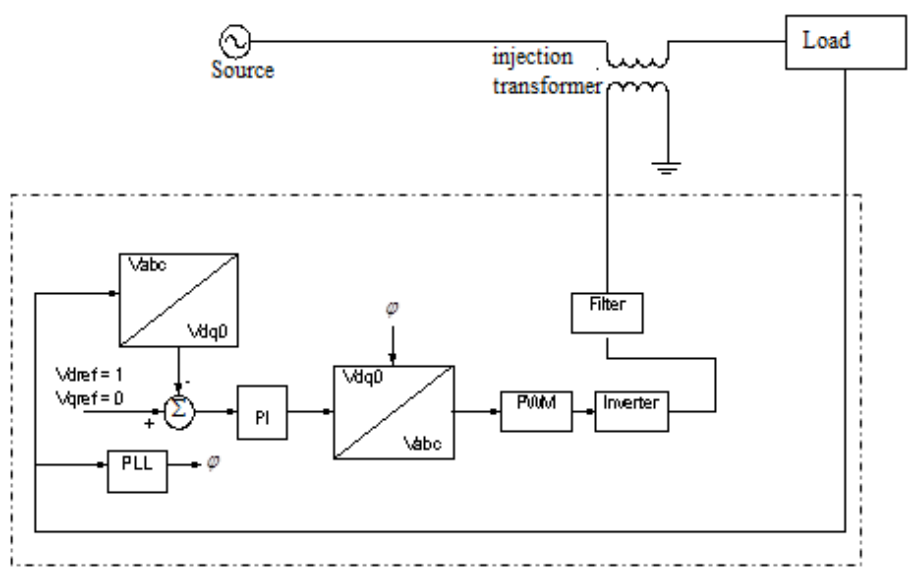

Fig.2. Block diagram of DVR design

SPWM is a comparison circuit between 3 phase sinusoidal signal and carrier signal. If a sinusoidal signal $>$ signals the carrier, it will generate a pulse 1 and if the sinusoidal signal $<$ carrier signal, it will generate a pulse 0. The pulse is by this SPWM which will activate the inverter. The carrier signal amplitude in this simulation is set to 1.25.

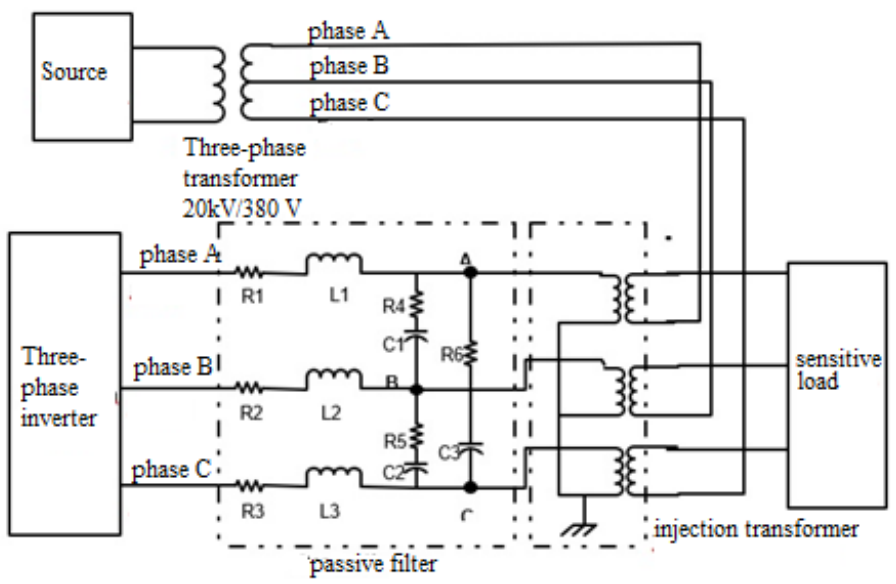

Fig.3. Design of three phase LC filter circuit

\section{Results and Discussion}

In this study, the distribution system of PT DSS power plant installed by the DVR is as shown in Figure 4. The DVR conneted in series with distribution system as compensator voltage sag that occurs.

The control system in this study serves to detect voltage disturbances. Load voltage is measured continuously which is then compared with the reference voltage using voltage loop control (PI). This controller has two constants, namely PC (Proportional Constant) and IC (Integral Constant). PC and IC are tuned until they reach the desired response.

The simulation design is modeled in the form of a distribution system of $20 \mathrm{kV} / 380 \mathrm{~V}$. When there is no one phase disturbance to the ground on a three phase supply voltage feeder $\left(\mathrm{V}_{\mathrm{A}}, \mathrm{V}_{\mathrm{B}}\right.$, and $\left.\mathrm{V}_{\mathrm{C}}\right)$ in a stable condition. 


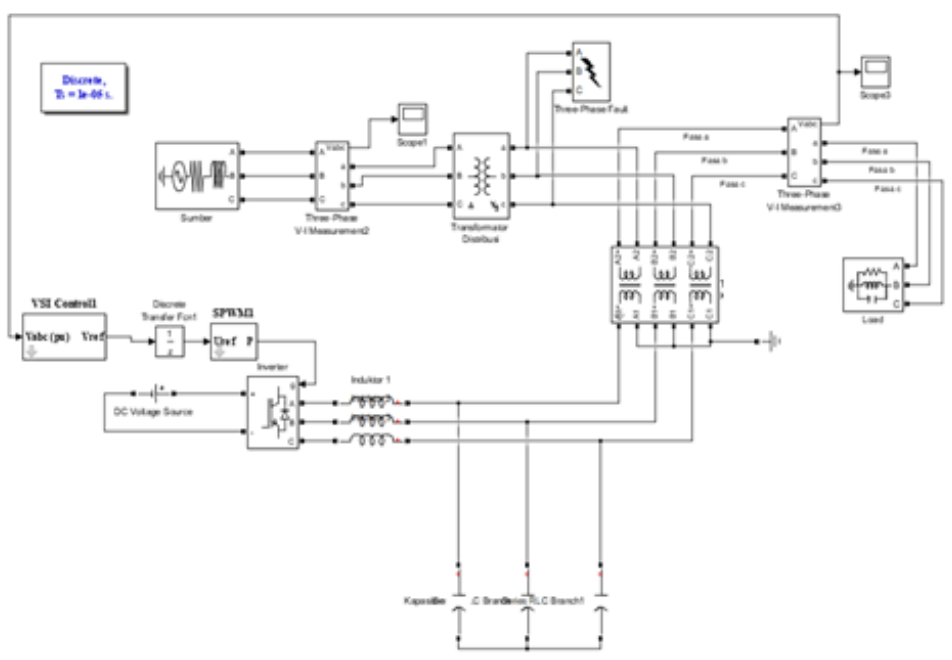

Fig. 4. System distribution with DVR
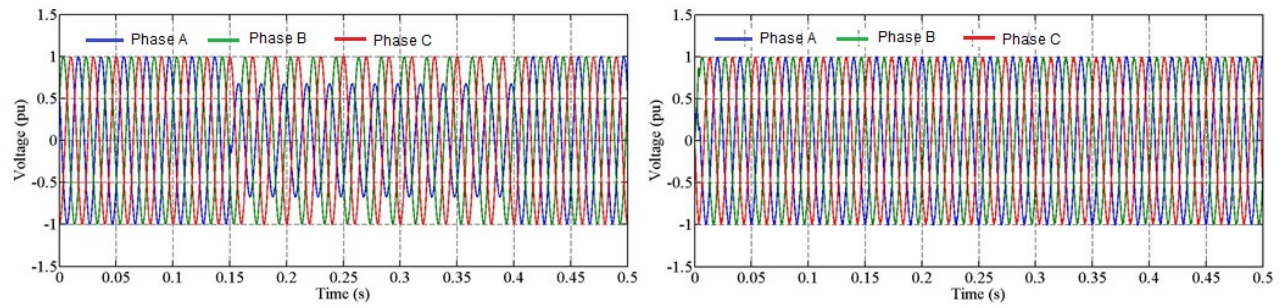

(a)
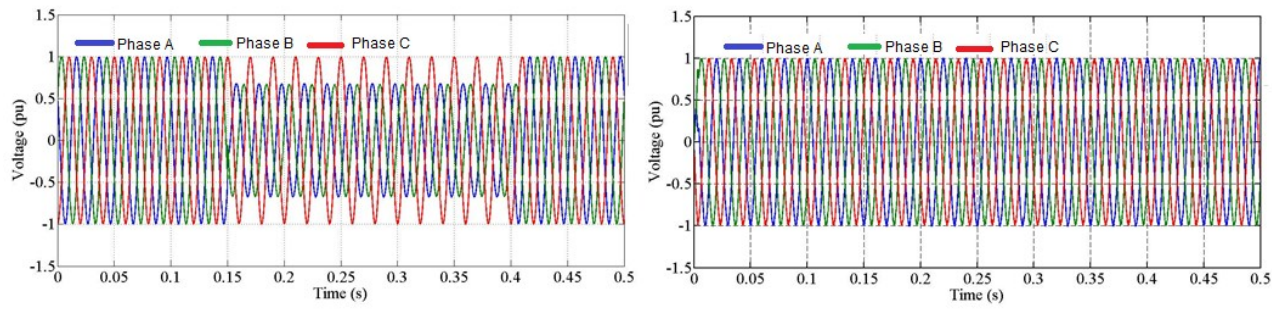

(b)
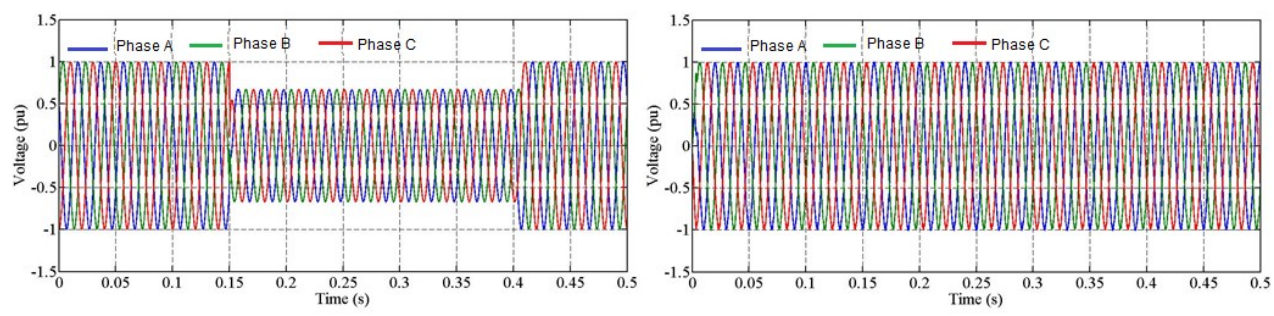

(c) 

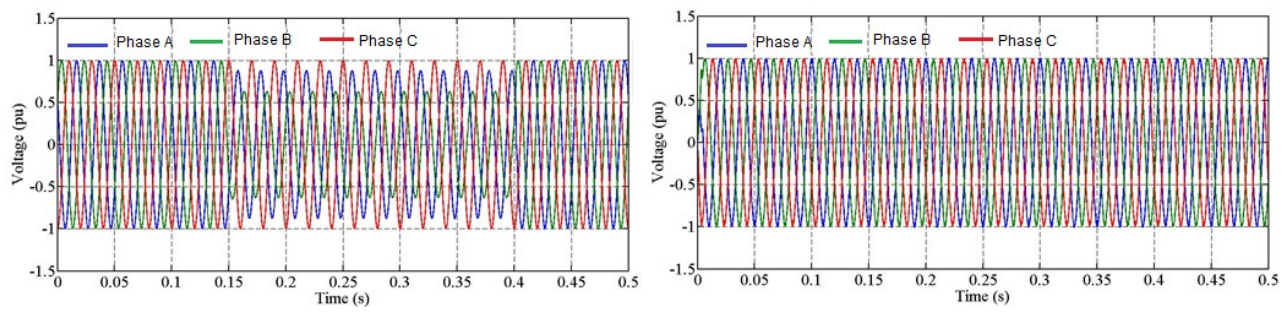

(d)

Fig.5. Simulation results with disturbances (a) single phase to the ground, (b) two phase to ground (c) three phase to ground and (d) phase to phase

Figure 5 (a) on the left is a simulation on a distribution system that experiences a single phase disturbance to the ground. There is voltage drop in the phase $(0.6779 \mathrm{pu})$ which disturbanced. The voltage drop is handled by the DVR with injecting voltage, and then occurred a recovery of power quality in the system like shown Fig.5.(a)on the right.

Figure 5 (b) the disturbance that occurs is a two-phase disturbance to the ground (phase $\mathrm{A}$ and phase B). There was a voltage decrease in phase A $(0.6786 \mathrm{pu})$ and phase B $(0.6645$ $\mathrm{pu}$ ). The installed DVR can cause recovery of voltage stability to $0.9954 \mathrm{pu}$.

Three-phase disturbance that occurs in the distribution system causes a voltage drop in all three phases. In this case there is a voltage drop in phase A to 0.6714 , phase B $(0.6698$ $\mathrm{pu})$ and phase $\mathrm{C}(0.6707 \mathrm{pu})$. The DVR can handled that disturbance and recovery the voltage at $0.9967 \mathrm{pu}$, like seen at Figure 5 (c).

Figure 5. (d) the last simulation is a simulation for phase-phase disturbance. Disturbance occurs between phase A and phase B. The voltage on phase A drops to 0.8778 pu and phase B drops to $0.6318 \mathrm{pu}$. After the DVR is installed on distribution system, the voltage recovery occurs at the point $0.9921 \mathrm{pu}$.

\section{Conclusion}

The simulation results show that the proposed DVR is capable of repairing power quality interference. The DVR control block will detect the disturbance of voltage that occurs and the DVR functions as a compensator. PT. DSS Power Plant often occurred short circuit fault. DVR works to inject voltage when the systems undergo voltage sag. DVR is capable of repairing voltage sag that occurs from $0.67 \mathrm{pu}$ to $0.99 \mathrm{pu}$ with recovery time of 0.25 seconds.

\section{References}

1. K. Sandhya, A. J. Laxmi, and M. P. Soni, "Design of PI and Fuzzy Controllers for Dynamic Voltage Restorer (DVR)," AASRI Procedia, vol. 2, pp. 149-155, (2012).

2. D. Tien, R. Gono, and Z. Leonowicz, "A Multifunctional Dynamic Voltage Restorer for Power Quality Improvement," Energies, vol. 11, no. 6, p. 1351, (2018).

3. K. Bhumkittipich and N. Mithulananthan, "Performance enhancement of DVR for mitigating voltage sag/swell using vector control strategy," Energy Procedia, vol. 9, pp. 366-379, (2011).

4. S. Khalid and B. Dwivedi, "Power Quality Issues, Problems, Standards \& Their Effects in Industry with Corrective Means," Int. J. Adv. Eng. Technol., vol. 1, no. 2, pp. 1-11, (2011).

5. S. P. Mishra, B. Biswal, J. P. Roselyn, and D. Devaraj, "Simulation and analysis of DVR for mitigating voltage sags and swells," Procedia Eng., vol. 64, pp. 341-350, (2013).

6. A. M. Saeed, S. H. E. Abdel Aleem, A. M. Ibrahim, M. E. Balci, and E. E. A. El-Zahab, "Power conditioning using dynamic voltage restorers under different voltage sag types," J. Adv. Res., vol. 7, no. 1, pp. 95-103, (2016). 
7. R. Ibrahim, A. M. A. Haidar, M. Zahim, and H. Iu, "The effect of DVR location for enhancing voltage sag," 2010 Int. Conf. Intell. Adv. Syst. ICIAS 2010, pp. 1-4, (2010).

8. A. J. Laxmi, K. U. Rao, M. Sushama, and N. T. Devi, "Hardware Implementation Of Single Phase Dynamic Voltage Restorer," pp. 204-209, (2010).

9. C. Benachaiba and B. Ferdi, "Power Quality Improvement Using DVR," Am. J. Appl. Sci., vol. 6, no. 3, pp. 396-400, Mar. (2009). 